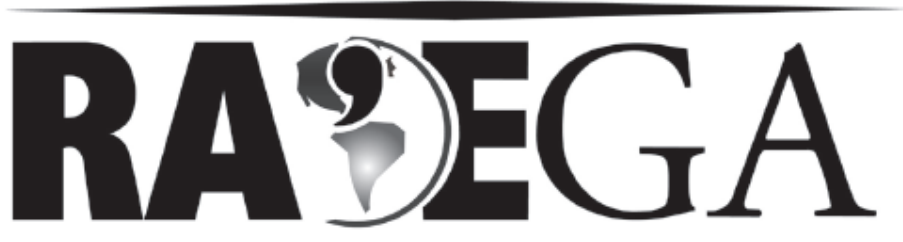

O ESPAÇO GEOGRÁFICO EM ANÁLISE

\title{
A PARTICIPAÇÃO COOPERATIVISTA DOS AVICULTORES NA REGIÃO OESTE PARANAENSE
}

\section{THE COOPERATIVIST PARTICIPATION OF THE AVICULTURISTS IN WESTERN PARANÁ.}

\author{
Diane Belusso $^{1}$
}

\section{RESUMO}

Este artigo trata da participação cooperativista dos avicultores na medida em que são eles associados das empresas integradoras. A partir da pesquisa realizada, foi evidenciado que a participação cooperativista envolve um maior nível de organização por parte destes agricultores, entretanto, eles compõem uma minoria do quadro geral das cooperativas, pois a avicultura é apenas uma das atividades econômicas com as quais os produtores podem participar em suas cooperativas. As cooperativas potencializam o poder de reivindicação dos agricultores junto ao governo, principalmente no direcionamento das políticas de crédito rural, interferindo na eficiência da utilização dos recursos e nas opções produtivas.

Palavras-chave: produtores integrados; empresas cooperativistas; avicultura industrial.

\section{ABSTRACT}

This study deals with the cooperative participation of the aviculturists as associated with integrating companies. From the survey, it was evident that the cooperative participation involves a higher level organization of these farmers.

\footnotetext{
${ }^{1}$ Doutora em Geografia pela Universidade Estadual Paulista "Júlio de Mesquita Filho" (FCT/UNESP), campus Presidente Prudente. Docente do Instituto Federal de Educação, Ciência e Tecnologia do Paraná, campus Umuarama. dianebelusso@yahoo.com.br
} 
However, they comprise a minority in the general framework of cooperatives, because poultry keeping is just one economic activity among diverse others. Cooperative enterprises intensify the farmers' claims to government, mainly for rural credit policies, interfering in the efficient use of resources and in the productive options.

Keywords: integrated producers; cooperative enterprises; poultry industry.

\section{Introdução}

Os resultados apresentados neste artigo são oriundos da pesquisa intitulada "A integração de agricultores às cooperativas agrícolas abatedoras de frangos no oeste do Paraná", realizada no período de 2007 a 2011 . Vinculada ao Programa de Pós-Graduação em Geografia da Universidade Estadual Paulista "Júlio de Mesquita Filho" (FCT/UNESP), em nível de doutorado, a execução da pesquisa contou com o apoio financeiro da Fundação de Amparo à Pesquisa do Estado de São Paulo (FAPESP).

Constituíram-se nos principais elementos motivadores deste estudo: a expansão da avicultura industrial no Brasil, sobretudo as inovações tecnológicas e o aumento de produtividade alcançado por este segmento agroindustrial a partir dos anos 1970, e a forte presença e estruturação de cooperativas agrícolas abatedoras de frangos na região Oeste Paranaense. $O$ presente artigo, entretanto, está focado nos principais aspectos da participação cooperativista dos avicultores.

Cinco grandes cooperativas agrícolas, fundadas nos anos 1960 e 1970, com sede em municípios localizados na Mesorregião Oeste Paranaense, implantaram várias agroindústrias, inclusive abatedouros de frangos, são elas: C.Vale Cooperativa Agroindustrial, de Palotina; Copacol - Cooperativa Agrícola Consolata, de Cafelândia; Copagril Cooperativa Agroindustrial, de Marechal Cândido Rondon; Coopavel Cooperativa Agroindustrial, de Cascavel; e Cooperativa Agroindustrial Lar, com sede em Medianeira. A Copacol atua no segmento avícola desde 1982 e a exemplo dela outras cooperativas investiram no setor. O empreendimento mais recente é o da Copagril, inaugurado no ano 
de 2005. A Coopavel iniciou com a avicultura em 1994, a C.Vale em 1997 e a Lar 1999.

Tais cooperativas possuem como principal área de atuação o Estado do Paraná, mas a C.Vale, a Copagril e a Lar possuem entrepostos ou filiais nos estados de Santa Catarina, Mato Grosso do Sul, Mato Grosso e no Paraguai. A localização dos parques industriais avícolas e a área de abrangência em relação aos produtores de frangos se restringem a municípios paranaenses.

De acordo com os dados fornecidos pelas cooperativas, em 2007, 0 número total de avicultores integrados às cooperativas pesquisadas era de 1.958. Foram entrevistados 86 proprietários de aviários no período compreendido entre o segundo semestre de 2008 e o primeiro semestre de 2009, distribuídos nos seguintes municípios: Palotina (35), Cafelândia (19), Marechal Cândido Rondon (07), Mercedes (05), Toledo (04), Itaipulândia (04), Corbélia (03), Cascavel (03), Ibema (01), Céu Azul (01), Matelândia (01) e Missal (01). Destes, 37 são integrados à C.Vale, 22 à Copacol, 16 à Copagril, seis à Lar e cinco à Coopavel. A utilização das entrevistas aparece no texto principalmente por meio de transcrições de trechos das respostas obtidas, cujos entrevistados são identificados por um número precedido da letra "E". Além dos avicultores foram realizadas entrevistas com os dirigentes das cooperativas.

Ao tratar de avicultores integrados faz-se referência à relação contratual entre produtores e agroindústrias, vinculada especificamente a um produto: os frangos de abate.

\section{A participação cooperativista dos avicultores}

A produção integrada é tecnicamente definida como uma forma de articulação entre empresas agroindustriais e produtores agrícolas, em que o processo de produção é organizado industrialmente, com aplicação maciça de tecnologia e capital (PAULILO, 1990).

Pode-se denominar produção integrada o envolvimento entre os agricultores/ proprietários de aviários, responsáveis pela engorda dos frangos, 
e as empresas integradoras que coordenam os contratos e industrializam a produção. A integração pode ser entendida, conforme Espíndola (1999): o fornecimento de pintainhos, rações, assistência técnica e garantia de compra dos frangos pela empresa, em contrapartida, o produtor deve cumprir as orientações técnicas e receber os insumos da empresa integradora.

Os produtores integrados assumem os custos da implantação dos galpões, da instalação dos aparelhos de climatização, da mão de obra, energia elétrica, maravalha, lenha e/ou gás, etc. As empresas integradoras são representadas pelos parques industriais avícolas (matrizeiros, incubatórios, fábricas de rações e abatedouros), pelos departamentos de assistência técnica e de controle da produção, verificação da conversão ração/carne e dos índices de eficiência produtiva que resultam no valor do pagamento. Os produtores são remunerados de acordo com a produtividade do lote de pintainhos ao final do ciclo produtivo, em torno de 45 dias.

A este modelo de integração, a denominação mais adequada é a de "quase-integração" (LOPES; NEVES; TROMBIN, 2007) ou contrato de parceria.

Do ponto de vista das empresas, se diz que o sistema de integração apresenta um alto custo de manutenção porque é necessário um elevado capital de giro para o financiamento do sistema e para a compra da matériaprima, entretanto, a integração se mostra eficiente e fundamental em relação ao fornecimento regular e padronizado e em relação aos preços relativamente baixos de matéria-prima, principalmente se existir uma estrutura regional oligopsônica em favor da agroindústria (ESPÍNDOLA, 1999).

No caso em que as empresas integradoras são as cooperativas, os produtores integrados são, também, associados/cooperados da empresa integradora. A produção de frangos é apenas uma entre as relações econômicas com as quais os associados podem participar de sua cooperativa.

As relações econômicas entre os cooperados e a sua empresa são então caracterizadas como ato cooperativo, e não como ato comercial. Ainda, as sociedades cooperativas são caracterizadas como sociedades de pessoas, nas quais há a 
agregação inicial do fator de produção trabalho (nas assembléias gerais cada associado tem direito a um único voto), utilizando posteriormente o fator de produção capital, diferentemente das sociedades de capital, que são caracterizadas pela agregação inicial do fator de produção capital (nas assembléias gerais o voto é proporcional ao capital de cada investidor).

Portanto, nas sociedades cooperativas, o cooperado assume, ao mesmo tempo, as funções de usuário da empresa e seu proprietário ou gestor, transferindo funções da sua economia individual para a empresa cooperativada (BIALOSKORKI NETO, 2006, p.38).

As cinco cooperativas agroindustrias do Oeste Paranaense recebem, armazenam e comercializam principalmente grãos e industrializam matériasprimas. No Quadro 01 observam-se os produtos recebidos e as indústrias de cada uma das cooperativas, a fim de comparação. Para a prestação de serviços, também faz parte da infra-estrutura das cooperativas: supermercados, lojas de peças e máquinas, posto de combustíveis, aviação agrícola, etc.

Quadro 01 - Os produtos recebidos e as agroindústrias das cooperativas do Oeste Paranaense.

\begin{tabular}{|c|c|c|}
\hline COOPERATIVAS & Produtos recebidos & Indústrias \\
\hline COPACOL & $\begin{array}{l}\text { Frangos, Suínos, Peixes, } \\
\text { Leite, Soja, Milho, Trigo e } \\
\text { Café. }\end{array}$ & $\begin{array}{l}\text { Complexo Industrial Avícola, Frigorífico } \\
\text { de Peixes e Unidade Produtora de } \\
\text { Leitões, Beneficiadora de café. }\end{array}$ \\
\hline COOPAVEL & $\begin{array}{l}\text { Frangos, Suínos, Bovinos, } \\
\text { Leite, Soja, Milho e Trigo. }\end{array}$ & $\begin{array}{l}\text { Complexo Industrial Avícola, Frigorífico } \\
\text { de Suínos, Frigorífico de Bovinos, } \\
\text { Fábrica de Rações, Fábrica de } \\
\text { Fertilizantes, Beneficiamento de } \\
\text { Sementes, Indústria de Laticínios, } \\
\text { Indústria de Óleos, Unidade Produtora } \\
\text { de Leitões. }\end{array}$ \\
\hline COPAGRIL & $\begin{array}{l}\text { Frangos, Suínos, Leite, Soja, } \\
\text { Milho e Trigo. }\end{array}$ & $\begin{array}{l}\text { Frigorífico de Frangos, Fábrica de } \\
\text { Rações. }\end{array}$ \\
\hline C. VALE & $\begin{array}{l}\text { Frangos, Suínos, Leite, Soja, } \\
\text { Milho, Trigo e Mandioca. }\end{array}$ & $\begin{array}{l}\text { Complexo Industrial Avícola, Fábrica de } \\
\text { Amido de Mandioca, Unidade Produtora } \\
\text { de Leitões. }\end{array}$ \\
\hline LAR & $\begin{array}{l}\text { Frangos, Suínos, Ovos, Leite, } \\
\text { Soja, Milho, Trigo, Mandioca } \\
\text { e Vegetais (milho doce, } \\
\text { mandioca de mesa, etc.). }\end{array}$ & $\begin{array}{l}\text { Complexo Industrial Avícola, Indústria } \\
\text { de farelo e óleo de soja, Indústria de } \\
\text { Beneficiamento de Sementes, Fábrica } \\
\text { de Fécula e Amido de Mandioca, } \\
\text { Indústria de Empacotados (arroz e } \\
\text { alimentos para pássaros), Fábrica de } \\
\text { Vegetais Congelados, Fábrica de } \\
\text { Rações, Unidade Produtora de Leitões. }\end{array}$ \\
\hline
\end{tabular}

FONTE: Relatórios das cooperativas. Org. da autora. 
Os produtos em comum recebidos pelas cinco cooperativas são: soja, trigo, milho, leite, suínos e frangos. Diferenciam-se entre os produtos recebidos: o café e os peixes, da Copacol e os vegetais e ovos, da Lar. A industrialização do leite e dos suínos é realizada pela cooperativa central Frimesa, exceto a Coopavel, que possui unidades industriais próprias para tais matérias-primas. O trigo é processado por outra cooperativa central, a Cotriguaçu. Além de receber produtos dos seus associados, as cooperativas também recebem de terceiros.

A estruturação de parques industriais para beneficiar e industrializar grãos e outras matérias-primas produzidas ou não pelos associados, segundo Serra (2008), representa a fase da industrialização das cooperativas e sua inserção ao Complexo Agroindustrial, cuja evolução passou a depender menos da representatividade e fidelidade do quadro associativo.

Na medida em que o parque industrial foi sendo estruturado e diante do risco de não ter matérias-primas em suficiência para manter as unidades de transformação em funcionamento constante, a cooperativa passou a trabalhar com terceiros e também com produtores integrados, comportamento que, se de um lado Ihe garantiu o suprimento de matérias-primas, de outro lado contribuiu para minimizar a importância do associado perante sua estrutura de funcionamento (SERRA, 2008, p.07).

Ser associado, nessas cinco cooperativas, é um requisito para os produtores integrados de frangos, diferentemente daqueles que entregam grãos e/ou compram insumos (sementes, fertilizantes), por exemplo, no caso de terceiros.

Os produtores de frangos integrados às cooperativas do Oeste Paranaense representam uma minoria em relação ao número de associados, de acordo com o Quadro 02.

O maior número de associados da C. Vale e da Lar deve-se a maior área de abrangência destas cooperativas. A C. Vale possui unidades em nove municípios do Oeste e Noroeste do Paraná, em sete do Mato Grosso, em oito do Mato Grosso do Sul e em três municípios de Santa Catarina e do Paraguai. Da mesma forma, a cooperativa Lar possui área de atuação em Santa 
Catarina, no Mato Grosso do Sul e no Paraguai, apesar de no Paraná estar a maioria dos associados das cooperativas.

Quadro 02 - Número total de associados e de produtores de frangos das cooperativas abatedoras do Oeste Paranaense.

\begin{tabular}{|c|c|c|}
\hline COOPERATIVAS & $\begin{array}{c}\text { Número de } \\
\text { associados }\end{array}$ & $\begin{array}{c}\text { Número de produtores de } \\
\text { frangos }\end{array}$ \\
\hline COPACOL & 4.362 & 861 \\
\hline COOPAVEL & 3.000 & 318 \\
\hline COPAGRIL & 3.803 & 215 \\
\hline C. VALE & 8.192 & 372 \\
\hline LAR & 8.344 & 411 \\
\hline
\end{tabular}

*Incluídos os produtores de frangos.

FONTE: Relatórios das cooperativas. Org. da autora.

Segundo Bialoskorski Neto (2006) o número de associados de uma cooperativa é uma variável importante quando se faz referência à participação cooperativista, pois, caso haja crescimento do número de associados freqüentemente por conta do crescimento econômico da cooperativa - haverá conseqüências na participação social dos membros e nos custos de governança corporativa.

[...] quanto maior a área geográfica de atuação maior é o número de associados e mais difícil para a organização cooperativa incentivar a participação, também mais difícil para o associado participar, até mesmo pelos custos individuais de deslocamento [...].

$[\ldots]$

Como exemplo, em uma cooperativa com 20 associados, o voto relativo de cada um deles apresenta $1 / 20$ de poder de decisão, podendo haver uma maior expressão nas assembléias gerais, mas em uma cooperativa com 1.000 associados, cada voto apresenta $1 / 1.000$ de poder de decisão e uma probabilidade de menor expressão em uma assembléia geral (BIALOSKORSKI NETO, 2006, p.152-153).

Neste raciocínio, hipoteticamente, ao separar o grupo de associados produtores de frangos, o poder de decisão do voto individual destes é relativamente mais representativo em comparação ao voto individual do grupo geral de associados, ou seja, no caso da Copacol: 1/ 861 é o poder de decisão 
de um associado produtor de frangos que, ao mesmo tempo, se considerado no grupo geral, será de 1/4.362.

O voto de cada um dos associados, independente do tipo de relação econômica, deve ter o mesmo poder de expressão, mesmo que a avicultura assuma maior importância diante dos outros segmentos nos quais a cooperativa atua. De acordo com as respostas dos dirigentes das cooperativas $^{2}$, a avicultura representa um complemento aos demais segmentos, portanto, ela é tão importante quanto os outros.

Com mais detalhes, o dirigente da $\mathrm{C}$. Vale respondeu que a avicultura está alcançando a importância da soja em termos de faturamento, isto é, com base no ano de 2007 , a soja gerou $26,95 \%$ do faturamento de $R \$ 1,4$ bilhão e o frango respondeu por 23,04\%, cuja tendência será crescer esse percentual na medida em que o abate for ampliado.

A cooperativa Lar, de acordo com o relatório e balanço social e patrimonial referente ao ano de 2008, também atingiu $R \$ 1,4$ bilhão de faturamento, cujo maior percentual correspondeu ao complexo da soja (31,9\%), em seguida os insumos (20,02\%) e em terceiro lugar o complexo de carnes, que gerou $16,8 \%$ do faturamento total da cooperativa, em 2008.

Da mesma forma, raramente os agricultores entrevistados dependem exclusivamente da produção de frangos para a geração da própria renda. Ocorre, geralmente, a especialização produtiva em torno de duas ou mais culturas.

De acordo com as respostas dos avicultores entrevistados, a produção agropecuária destinada à comercialização ocorre com os seguintes produtos, além do frango: soja, milho, trigo, leite, suínos, mandioca, peixes, feijão, eucalipto, caprinos, bovinos, aveia, sorgo, amendoim, pipoca, fumo, girassol e cana-de-açúcar. As culturas mais freqüentes, desenvolvidas por um mesmo produtor, verificam-se no Gráfico 01.

\footnotetext{
${ }^{2}$ Foi formulada a seguinte questão: entre outros segmentos que a cooperativa atua, pode-se dizer que a avicultura é o mais importante? Por quê?
} 


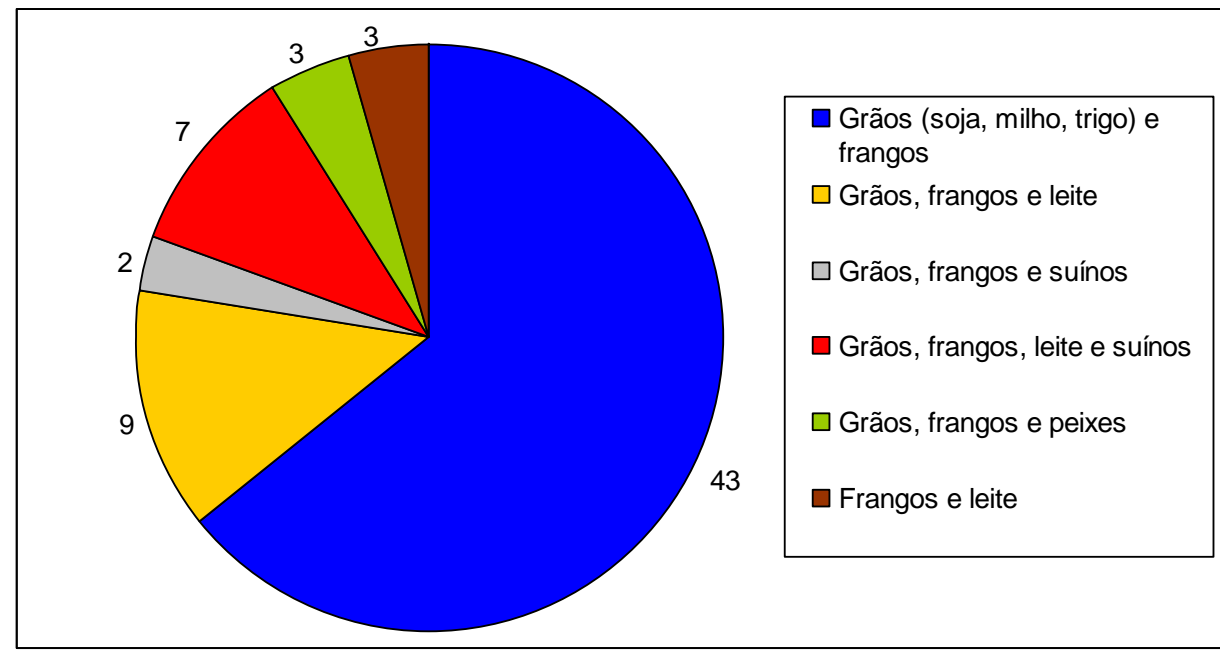

Gráfico 01 - Combinações de culturas mais freqüentes desenvolvidas por um mesmo produtor.

FONTE: Pesquisa de campo (2008 e 2009).

$\mathrm{Na}$ maioria dos casos se verificou que a produção de frangos é desenvolvida em conjunto com as lavouras de grãos, principalmente soja, milho e trigo.

Destaca-se que, embora em menor proporção, uma parcela dos produtores (31\% dos entrevistados) possui também rendimentos oriundos de atividades não-agrícolas ou exercem outra profissão, o que significa uma menor dependência em relação ao rendimento da avicultura. Maiores detalhes sobre a caracterização dos produtores de frangos integrados às cooperativas do Oeste Paranaense foram apresentados em Belusso (2011).

Ainda, sobre o poder de decisão dos associados, questionou-se quanto à participação nas assembléias. Entre os 86 entrevistados, as respostas chegaram ao resultado seguinte: 64 afirmaram que participam, 12 produtores disseram que às vezes participam e 10 produtores responderam que não comparecem às assembléias gerais das cooperativas.

Os principais motivos da não participação, conforme os relatos são: porque a cooperativa é longe; impossibilidade de se ausentar do trabalho; não tem motivação para participar, pois está tudo decidido, só vão para ouvir. 
Por exemplo, o motivo do não comparecimento às assembléias, de acordo com um avicultor entrevistado:

"[...] porque está tudo mastigado, é só ir lá e escutar, não adianta a gente participar. Na cooperativa, se quiser falar alguma coisa tem que participar dos comitês educativos e, daí, já tem a 'panela' deles, ninguém põe mais nada. Então, não adianta participar porque você só fica se bobeando lá. Já falei: não participo e pronto" (E30).

A maioria dos produtores pesquisados, que responderam sim, comparece às assembléias pelos seguintes motivos: obter informações sobre a situação financeira da empresa, sobre as perspectivas de negócios e investimentos; porque sente necessidade de se manter atualizado.

Segundo o SESCOOP (2009), a Assembléia Geral é a reunião anual dos associados das cooperativas; é o órgão supremo da entidade; é o local e o momento para escutar informações, aprovar projetos, aprovar a distribuição das sobras e eleger o Conselho Administrativo e Fiscal, entre outras comissões. É comum a realização de pré-assembléias em cada unidade da cooperativa, que são reuniões preparatórias antes da Assembléia Geral. Aí entra a função dos Comitês Educativos que são órgãos consultivos assessores do conselho administrativo, formados por associados líderes, na sede da cooperativa e em cada uma das unidades.

Os objetivos dos comitês são: incentivar a participação dos associados, informar sobre serviços oferecidos pelas cooperativas e sobre as diretrizes e decisões dos dirigentes (SESCOOP, 2009), ou seja, os associados recebem as orientações sobre quais serão as decisões tratadas na Assembléia Geral e, com antecedência, tem a oportunidade de formular discussões que serão repassadas, pelos líderes, ao Conselho de Administração.

Entre os produtores de frangos pesquisados, alguns são membros dos comitês educativos e, entre estes, se destacou trechos de respostas que demonstram as diversas opiniões quanto às decisões da cooperativa, à participação em assembléias e se estão favoráveis ou contrários: 
"É... Sempre têm uns 'contrinha'... Sempre vai ter alguma coisa que você não concorda, mas quem decide é a maioria" (E3).

Outro produtor comentou:

"Faço até parte do comitê... Isso é uma organização que não manda nada, não faz parte de diretoria, não é nada, só participa ativamente" (E29).

No mesmo sentido, um produtor que não é membro de comitê, disse:

"Eu não gosto muito de participar de discussões lá dentro da cooperativa, já me convidaram, mas eu não quis. Sou contra a instalação de associação que se refere a discutir problemas do frango... Eu tenho acesso ao técnico, ao responsável do setor e se for preciso todo produtor de frango tem acesso à presidência se houver necessidade de discutir problema do frango" (E8).

Outro avicultor comentou não ter faltado nenhuma assembléia:

"Até hoje acho que não faltei nenhuma. Como associado é obrigação do associado participar das assembléias, então, eu acho que a cooperativa é nossa, se não vamos participar das assembléias estamos fugindo do nosso direito de levar reivindicação. É, hoje, se não fosse a cooperativa seria pior, talvez, é um mal necessário, às vezes tem coisa que a gente critica, mas se não fosse a cooperativa seria pior, então, eu acho que a cooperativa veio em boa hora" (E2).

Ao dar opinião quanto às decisões que são tomadas nas Assembléias Gerais, uma proprietária que não está totalmente de acordo com a cooperativa comentou sobre a criação de uma associação por parte de um grupo de avicultores:

"Muitas decisões não, até está tendo uma associação pra discutir sobre o frango, pra melhorar, pra ver se eles conseguem (...) tipo assim, quando é pra instalar alguma coisa no aviário, se consegue mais em conta, porque a cooperativa não fica ligando pra essas coisas. Então, foi montada uma equipe e está tendo a cada mês reuniões pra ver se vai dar certo, esta associação" (E5). 
O fato de estar satisfeito ou insatisfeito com as negociações executadas pelos conselhos de administração das cooperativas é uma evidência das relações de poder e da força de onde emanam as decisões. Também depende do modo individual de entender a cooperativa, conforme estes entrevistados:

"Eu estou de acordo sim, acho que a cooperativa está no rumo certo, no meu modo de ver" (E19).

"A cooperativa deveria dar mais condições para o agricultor crescer. Muitas vezes, a própria lavoura, vai ficando de ano pra outro as dívidas, vai renovando dívida. Eu acho que, com o potencial que a cooperativa tem hoje, ela teria como aliviar essas coisas, não dar de graça na hora de comprar os insumos, mas, na hora da venda, valorizar mais os produtos dos associados. Eu vejo dessa forma, precisaria não pensar mais como uma empresa e olhar mais para o associado que foi quem começou, deveria fortalecer mais o cooperativismo" (E13).

Além da participação nas assembléias foi questionado se freqüentam outros eventos, cursos ou treinamentos promovidos pelas cooperativas. Entre os produtores pesquisados, 27 responderam que não e 59 responderam que sim e informaram que o próprio produtor ou alguém de sua família já freqüentou algum curso promovido por meio da cooperativa, tais como de: computação; regulagem de máquinas, pulverização; administração rural; qualidade total; oratória, artesanato, culinária, etiqueta, além dos tradicionais dias de campo e eventos esportivos (mini-olimpíadas).

[...] a cooperativa é uma instituição que promove a participação e a aproximação entre os produtores rurais. Esta aproximação fortalece os laços horizontais entre os cooperados em um mesmo local, acontecendo nesta ocasião a troca de informações. A participação em cursos e treinamentos fortalece também os laços verticais, possibilitando assim que os cooperados adquiram novos conhecimentos sobre a sua atividade (SALANEK FILHO, 2007, p.130).

De acordo com as observações durante os trabalhos de campo é perceptível que o nível de satisfação dos associados com a cooperativa depende da própria satisfação com a atividade agrícola que desenvolve e se 
relaciona às condições e à realidade pela qual estão passando. Os associados reconhecem as funções da cooperativa, mas, no fundo, sabem que os seus problemas não passam por soluções simples. São comuns os produtores que reclamam do governo, da política, da economia e das leis.

Qualquer organização cooperativista, por definição, é indissociável do seu quadro de associados. Segundo Bialoskorski Neto (2006), do ponto de vista econômico, as cooperativas não possuem uma independência autônoma e independente dos seus membros e devem servir às necessidades das economias particulares dos associados. Entretanto, existem problemas de participação quando a gestão administrativa é profissionalizada, quando se prioriza a eficiência econômica, julgando demandas sociais que poderiam causar ineficiência para a cooperativa (BIALOSKORSKI NETO, 2006).

O foco econômico implica em cooperativas com grande poder de mercado, e que para ganhar em competitividade tem na estratégia de crescimento a sua principal característica. Essa estratégia pode garantir eficiência econômica e de escala e escopo, mas induz ao crescimento do número de cooperados.

É comum haver cooperativas que apresentam um número grande de associados, assim, os problemas de fluxo de informação e de participação são relevantes e a organização poderá estar isolada da realidade dos membros, bem como os membros também isolados da cooperativa e da realidade da administração (BIALOSKORSKI NETO, 2006, p.198-199).

Em termos de implantação de parques industriais, Serra (2008) demonstrou que não existe uma relação direta entre o crescimento da cooperativa e a participação dos associados ao levar em consideração que: dificilmente uma cooperativa capta recursos diretamente entre os associados para custear investimentos.

Isto significa que a consolidação do parque industrial e da própria cooperativa como empresa não dependeu da expropriação direta dos produtores associados, tendo relação maior com benefícios carreados pelo Estado através de financiamentos subsidiados e com o grau de eficiência da diretoria na condução de uma política de investimentos (SERRA, 2008, p.08). 
A fonte de recursos para a implantação dos complexos industriais avícolas, segundo as cooperativas pesquisadas, foram financiamentos obtidos nas seguintes instituições financeiras: Banco Regional de Desenvolvimento do Extremo-Sul (BRDE), Banco do Brasil, Banco Nacional de Desenvolvimento Econômico e Social (BNDES), além de complemento com recursos próprios, em alguns casos.

O BRDE é um importante parceiro das cooperativas agrícolas paranaenses a partir da década de 1970, primeiramente com investimentos em armazenagem e nas décadas seguintes em agroindústrias. Entre 2001 e 2009, cerca de $\mathrm{R} \$ 6$ bilhões investidos pelas cooperativas do Paraná foram repassados por meio do BRDE (OCEPAR/SESCOOP-PR, 2010).

Em junho de 2010, a Ocepar informou sobre um contrato, no valor de $R \$$ 407 milhões, assinado entre o BRDE e dezoito cooperativas paranaenses incluídas as cinco cooperativas abatedoras de frangos pesquisadas ${ }^{3}$. 0 montante será destinado para: capital de giro das empresas, melhoria da infraestrutura e expansão das agroindústrias. Trata-se de recursos do BNDES repassados por meio de linhas oficiais do governo federal: o Programa de Desenvolvimento Cooperativo para Agregação de Valor à Produção Agropecuária (Prodecoop) e Programa de Capitalização das cooperativas de produção agropecuária (Procap-Agro) (OCEPAR/SESCOOP-PR, 2010). ${ }^{4}$ Segundo informações da Ocepar (OCEPAR/SESCOOP-PR, 2010), a cooperativa Lar e a Copacol receberam os maiores repasses: a Lar recebeu $R \$$ 63,5 milhões que serão investidos na ampliação do abate de frangos e da produção de ração, também investirá em plantio de eucaliptos; a Copacol contratou $R \$ 54,5$ milhões que serão aplicados na construção de uma fábrica de óleo e farelo de soja, que começará a operar em 2012.

\footnotetext{
3 As cooperativas beneficiadas são: Castrolanda, Capal, Agrária, Cocamar, Integrada, Confepar, C.Vale, Coopavel, Copagril, Copacol, Lar, Frimesa, Cotriguaçu, Tradição, Coamo, Coasul, Batavo e Cocari.

${ }^{4}$ O Prodecoop tem prazo de doze anos, dois anos de carência e juros de $6,75 \%$ ao ano e o Procap-Agro tem prazo de seis anos, dois anos de carência e juros de 6,75\% ao ano.
} 
[...] a utilização do parque industrial, adquirido em nome dos associados, para a transformação de matérias-primas entregues por terceiros (agricultores não-associados), bem como sua locação para outras empresas, em momentos de ociosidade das máquinas, são situações que geram agregações de valores em benefício apenas da cooperativa, mas não de seus associados, considerando que não foi deles ou não saiu de suas propriedades a mercadoria transformada. Ora, não havendo a expropriação direta e também não havendo a utilização exclusiva dos equipamentos em função dos produtores filiados ou de suas mercadorias agrícolas, em parte deixa de haver a esperada sintonia entre o desempenho da cooperativa e o repasse de seus benefícios, na forma monetária, para o corpo associativo, embora, pelo menos teoricamente, esses sejam os verdadeiros donos da empresa (SERRA, 2008, p.09).

Para Bialoskorki Neto (2006), é um problema o fato de os resultados da cooperativa beneficiar, também, membros não associados: "[...] se percebido por outros agentes, não produz incentivos à participação na cooperativa, já que a participação gera custos de participação, e os benefícios são públicos e comuns" (BIALOSKORSKI NETO, 2006, p. 56).

Esses problemas ocorrem por conseqüência da não-definição precisa de direitos de propriedade na organização, uma vez que os usuários são ao mesmo tempo proprietários, e os direitos sobre o resíduo das operações não são definidos claramente, dependem de decisão, não são transferíveis e, portanto, também não sofrem valoração. [...]

Esse problema de definição é conseqüência de direitos igualitários à decisão na organização, que se diluem no processo de crescimento econômico, portanto, não há de modo transparente o direito sobre a propriedade, como também sobre as decisões desta organização, bem como o direito sobre os resultados oriundos desta (BIALOSKORSKI NETO, 2006, p.57).

Salanek Filho (2007), em seu estudo sobre os associados da Copacol, concluiu que o principal motivo da entrada dos produtores na cooperativa é o aspecto econômico, tendo como fator principal a facilidade para comercializar a produção. "Enquanto lhe for conveniente no aspecto econômico e a cooperativa defender os interesses do seu grupo de associados, existirá o 
interesse individual, o qual proporcionará o ganho coletivo" (SALANEK FILHO, 2007, p.145).

O cooperativismo, como pensamento reproduzido pela sociedade, pode gerar práticas diferenciadas. Muitas vezes, o incentivo à competitividade e a pouca compreensão sobre a teoria (o cooperativismo) e a prática (a cooperativa), induzem ao comportamento passivo dos associados ou ao comportamento de ganho individual em detrimento do ganho coletivo, o que poderia desestimular o fortalecimento deste modelo de associação de agricultores.

A avicultura de abate é uma atividade em potencial crescimento no Oeste Paranaense, seja pelas condições regionais favoráveis, mas, principalmente, pela função que as cooperativas desenvolvem ao optar pela implantação de parques industriais neste segmento produtivo, direcionando os tipos de cultivos de maneira que os associados possam participar do crescimento da cooperativa e usufruir os seus benefícios.

O apoio dos associados para o crescimento da cooperativa é fundamental do ponto de vista que: são os associados que fomentam a produção que será processada nos parques industriais. O interesse do produtor se sobressaiu nesta fala:

"Além da agricultura, a gente vê que é uma diversificação que tem que se fortificar aqui na nossa região, porque a gente como associado da $C$. Vale, ela investiu bastante e parece que a gente também tem que fazer essa parte da produção" (E13).

Os associados diretamente beneficiados pela implantação de complexos industriais avícolas são os integrados à produção de frangos, além dos produtores de soja e milho, matérias-primas com as quais são fabricadas as rações.

Existem razões que convencem os associados a se integrarem à produção de frangos, logicamente, o principal motivo é o interesse em aumentar a rentabilidade, melhorar a condição econômica e, para isto, a empresa integradora necessariamente não precisaria ser uma cooperativa. A conquista, pela cooperativa, da imagem de uma empresa sólida também os motiva, assim como o fato de os próprios presidentes das cooperativas e 
membros da diretoria possuir aviários, ou seja, se também investiram aqueles que detêm a gestão administrativa da cooperativa, se confia que haverá comprometimento com a atividade.

[...] o elemento rendimento é muito importante, mas o aspecto da segurança é fundamental. Os investimentos elevados que as culturas exigem, os riscos constantes, a incerteza dos preços são profundamente preocupantes. O integrado não está totalmente livre disso, no entanto os riscos na integração são menores. Por isso, a empresa integradora se utiliza fundamentalmente desse elemento na criação de relações complexas e de poder (TEDESCO, 2001, p.144).

Destaca-se a opinião emitida por um proprietário de aviários:

\begin{abstract}
"A segurança nossa, do produtor, está alicerçada também na garantia de renda, porque os próprios presidentes, diretores da cooperativa são proprietários de aviários. Quer dizer, se nós temos a segurança de ser uma empresa sólida, nós temos mais a segurança de que os próprios diretores são produtores. O presidente, vice-presidente, secretário e outros diretores que exercem funções importantes lá dentro têm aviários. Então pra nós isso é uma segurança dupla" (E8).
\end{abstract}

A partir deste comentário é possível deduzir que os avicultores compõem uma camada privilegiada do quadro de associados.

Os diversos produtores são iguais enquanto categoria de associados à cooperativa e integrados à produção de frangos, no entanto, perante a condução administrativa, seu posicionamento como diretoria ou a maior quantidade de produção entregue à cooperativa, diferencia-os na participação cooperativista e no nível de dependência e subordinação que lhe é imposto.

Os produtores interessados em se integrarem às cooperativas construindo aviário(s) precisam ser associados e ter disponibilidade financeira para realizarem os investimentos necessários. No Quadro 03 são apresentados os modelos e custos de implantação dos aviários, segundo informação da C.Vale, com base no ano de 2006. 
Quadro 03 - Modelos e custos para construção de aviários em 2006.

\begin{tabular}{|l|r|r|}
\hline \multicolumn{1}{|c|}{ MODELO } & Capacidade (frangos) & \multicolumn{1}{c|}{ Custo (R\$) } \\
\hline Climatizado & 30.500 & $320.000,00$ \\
\hline Climatizado & 24.000 & $270.000,00$ \\
\hline Semi-climatizado & 21.000 & $206.000,00$ \\
\hline Semi-climatizado & 16.500 & $170.000,00$ \\
\hline Convencional & 16.500 & $130.000,00$ \\
\hline Convencional & 13.500 & $106.000,00$ \\
\hline Convencional & 10.000 & $82.000,00$ \\
\hline Convencional & 7.000 & $62.000,00$ \\
\hline
\end{tabular}

Fonte: Imprensa C.Vale, 2006. Org. da autora.

$\mathrm{Na}$ maioria, a fonte do montante necessário para a construção de aviários é o crédito bancário. Verificou-se entre os produtores pesquisados que setenta e oito proprietários de aviários, ou seja, $90 \%$ do total entrevistado, afirmaram que os recursos foram financiados, mediante hipoteca para assegurar a dívida e com prazo de pagamento, geralmente, de oito anos.

Até o período das entrevistas, vinte e sete produtores, que corresponde a 31\%, responderam ter findado o pagamento de qualquer dívida vinculada aos aviários. Quase todos utilizaram o prazo máximo, mas há relatos de produtores que venderam algum imóvel para quitar a dívida antes do vencimento e evitar juros. Ocorre, também, que proprietários de aviários mais antigos possuem financiamentos vigentes não em relação à construção dos galpões, mas referentes a alguma reforma ou instalação de aparelhos novos. O questionamento que foi feito aos proprietários de aviário, sobre financiamento, englobou qualquer financiamento, seja de $100 \%$ do investimento, valor parcial ou para reformas posteriores.

O início e a manutenção dos produtores nesta atividade são dependentes do acesso ao crédito e este impõe condições mínimas de endividamento, por exemplo, um produtor que faz um empréstimo de $\mathrm{R} \$ 320$ mil (custo do aviário) deve ter à disposição 150\% deste valor como garantias.

Historicamente, as negociações quanto ao preço do alqueire de terra, na região oeste do Paraná, são proporcionais ao preço da saca de soja $(60 \mathrm{~kg})$, que varia em torno de 1.500 sacas por alqueire, nas áreas mais valorizadas. Considerando a cotação de $R \$ 50,00$ para uma saca de soja, um alqueire de 
terra estaria valendo $\mathrm{R} \$ 75$ mil, ou seja, o produtor deveria dispor, no mínimo, de seis alqueires de terra para garantir $150 \%$ do valor do empréstimo ( $R \$ 480$ mil), imaginando que a sua propriedade se localize nas áreas mais valorizadas. $^{5}$

Portanto, a propriedade de terra como um bem fixo, é um fator seletivo para a participação dos associados que objetivam produzir frangos para as cooperativas e que dependem do acesso ao crédito bancário.

A composição fundiária do quadro geral dos associados das cooperativas é verificada nos gráficos: 02, 03, 04 e $05{ }^{6}$

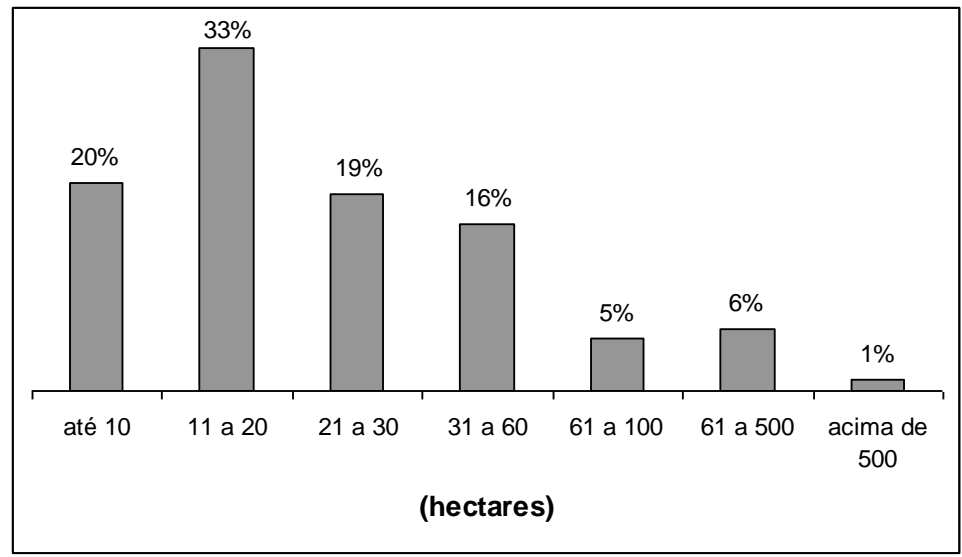

Gráfico 02 - Composição fundiária dos associados da Cooperativa Lar (2007). FONTE: LAR, Relatório Anual, 2007, p.12.

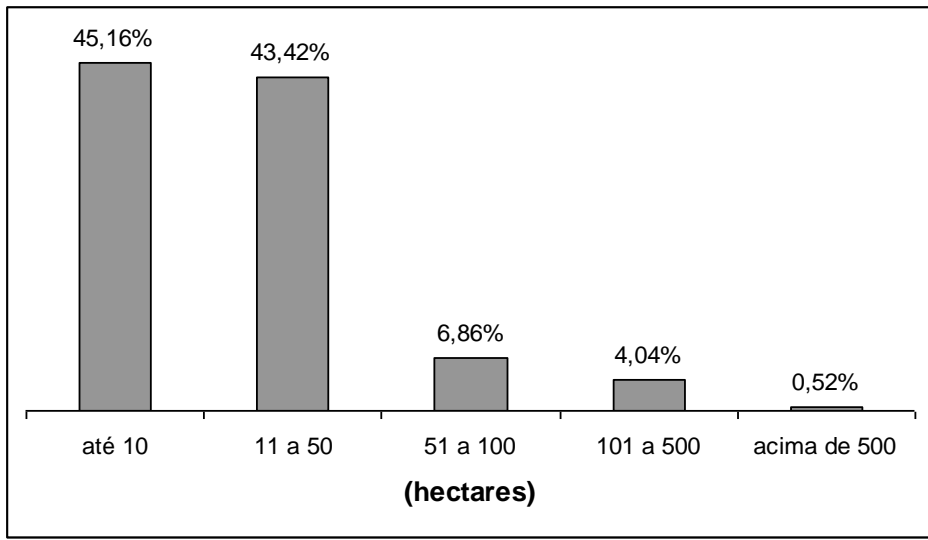

Gráfico 03 - Composição fundiária dos associados da Copacol (2006). FONTE: COPACOL, Balanço Social, 2006, p.22.

\footnotetext{
${ }^{5} \mathrm{O}$ preço de um alqueire de terra, no oeste do Paraná, varia entre 1.000 e 1.500 sacas de soja. Em relação à unidade de medida, seis alqueires (paulista) equivalem a 14,52 hectares.

${ }^{6}$ Estão incluídos nas estatísticas fornecidas pelas cooperativas os associados de toda a área de abrangência das cooperativas, exceto a $\mathrm{C}$.Vale, cuja composição fundiária se refere apenas aos associados do Paraná. A Coopavel não disponibilizou a informação.
} 


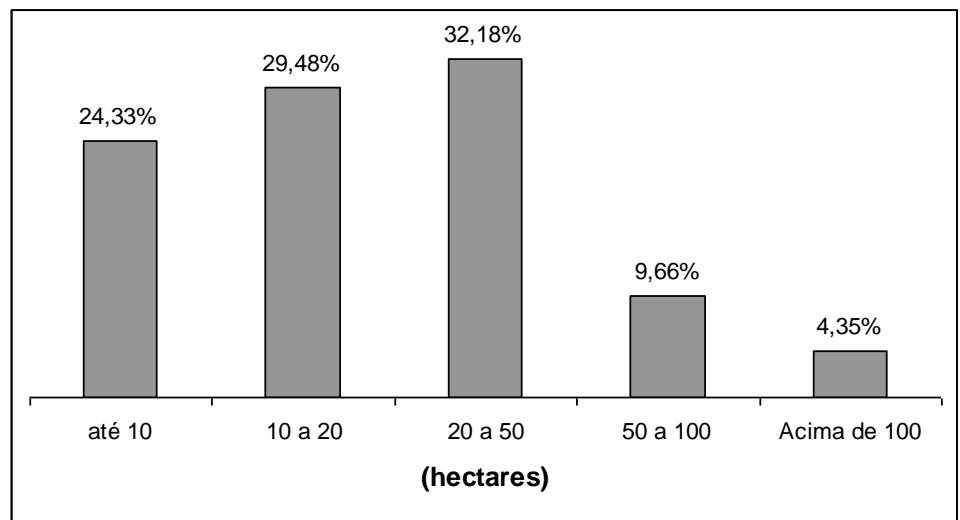

Gráfico 04 - Composição fundiária dos associados da Copagril (2007). FONTE: COPAGRIL, Relatório Anual, 2007, p.11.

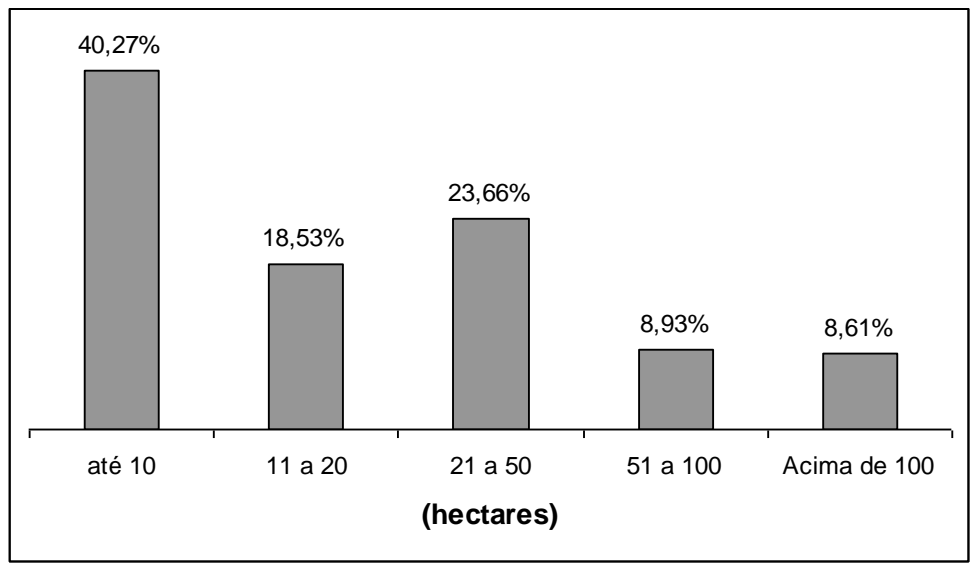

Gráfico 05 - Composição fundiário dos associados da C.Vale, no Paraná (2006). FONTE: Imprensa C.Vale, 2006.

Verifica-se que a maioria dos associados das cooperativas posiciona-se nos estratos abaixo de 50 hectares e o percentual de associados que possuem até 10 hectares é representativo.

Quanto à dimensão das propriedades dos avicultores entrevistados, verifica-se o Gráfico 06 e observa-se que a maioria das propriedades é de até 30 hectares, sendo que 12 hectares foi a dimensão mais freqüente entre as respostas. A pergunta feita aos produtores foi sobre a área total de terras que possuem, pois, em alguns casos, os produtores possuem mais de um estabelecimento além daquele onde se encontra instalado(s) o(s) aviário(s). Às vezes, também possui dois estabelecimentos e em ambos há aviários. 


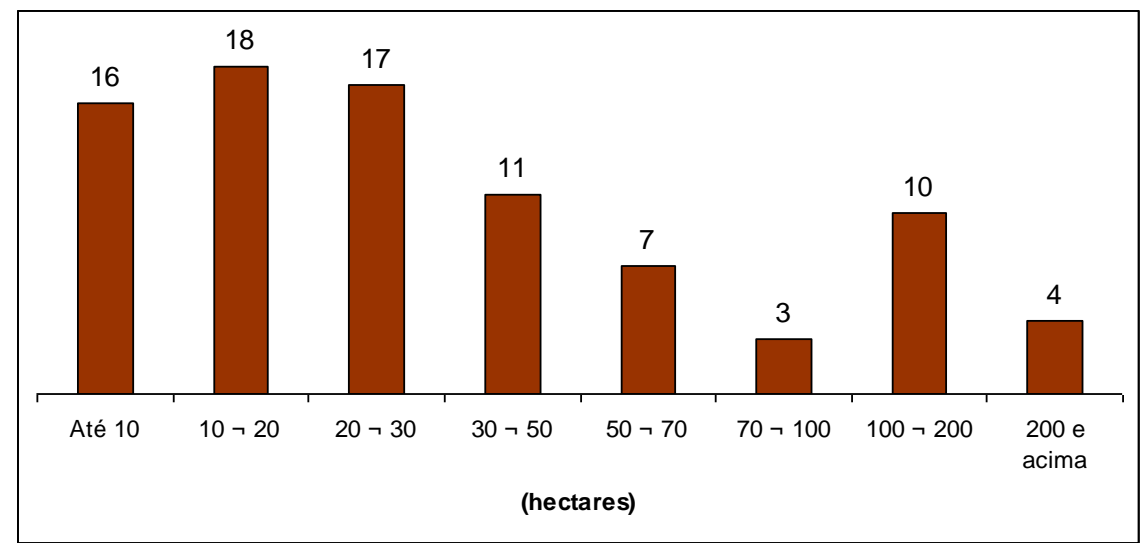

Gráfico 06 - Dimensão das propriedades dos produtores de frangos. FONTE: Pesquisa de campo (2008 e 2009).

A partir do exemplo citado anteriormente sobre a capacidade de endividamento, em relação ao custo do aviário e à propriedade dos produtores, é possível supor uma maior dificuldade de investimento para os associados com menos de 10 hectares. Tal suposição pode ser discutível de acordo com as condições do empréstimo e com a função das cooperativas como facilitadora do acesso ao crédito, seja concedendo aval aos associados, recebendo como garantia a penhora da produção ou por meio de consultoria à elaboração de projetos e orçamentos.

O Banco do Brasil disponibiliza um convênio para empresas integradoras que industrializam, beneficiam ou comercializam produtos agropecuários, é o Convir (Convênio de Integração Rural). O Banco do Brasil financia despesas de custeio e investimento para produtores integrados a essas empresas (agroindústrias, cooperativas de produção agropecuária, tradings) por meio das linhas de crédito rural. São beneficiários, os produtores que atendam às exigências para operar com o banco e também às exigências da empresa integradora. ${ }^{7}$

Recursos financeiros provenientes do Banco Regional de Desenvolvimento do Extremo-Sul (BRDE) e do Banco Nacional de Desenvolvimento Econômico e Social (BNDES) são captados pelas

\footnotetext{
${ }^{7}$ Informações obtidas no site do Banco do Brasil. <http://www.bb.com.br/portalbb/> Acesso em 12/08/2009.
} 
cooperativas do oeste do Paraná tanto para a implantação de abatedouros como para a construção de aviários pelos produtores, por meio de linhas de crédito específicas com juros mais baixos e maiores prazos.

Por exemplo, uma linha de financiamento do BRDE, ofertada durante a feira anual agropecuária da Coopavel (Show Rural 2010), conforme a notícia: "BRDE traz ao Show Rural o juro de financiamento mais baixo do mercado", veiculada no "Informe Diário da Ocepar" do dia 12 de fevereiro de 2010:

O Banco Regional de Desenvolvimento do Extremo-Sul (BRDE) está trazendo para esta edição do Show Rural financiamentos com uma taxa de juros fixa anual de $4,5 \%$ destinada à aquisição de máquinas e equipamentos novos e de fabricação nacional para uso no campo, inclusive para aviários. Este tipo de financiamento conta com recursos do BNDES dentro do Programa de Sustentação do Investimento (PSI). [...] Esta linha de crédito foi criada no ano passado, no auge da crise econômica, para oferecer recursos com baixos custos aos empresários e produtores rurais. O Ministério da Fazenda anunciou, inclusive, que a linha somente será ofertada até o final do primeiro semestre de 2010, uma vez que os efeitos da crise estão se diluindo (OCEPAR; SESCOOP-PR, 2010).

A avicultura industrial de abate, assim como outros segmentos do agronegócio, exemplifica a concentração de benefícios provenientes do crédito rural no Brasil. Dado o alto índice de produtores, no Oeste Paranaense, que aderiram ao financiamento para a produção de frangos, verifica-se o caráter seletivo e setorial das políticas públicas destinadas à agricultura e ao campo.

Apesar de boa parte dos países da América do Sul não contarem com um sistema de parceria tão difundido como no Brasil, é perceptível que o crescimento potencial da indústria de carne de frango nos mais diferentes países possibilitou o surgimento de empresários rurais capitalizados ligados ao setor. [...] Em todos os países investigados [da América do Sul], verifica-se a presença de associações de produtores que exercem pressões sobre o governo para a implantação de políticas em defesa da avicultura (ESPÍNDOLA, 2009, p.16).

São exemplos destas associações, para defender interesses setoriais, no Brasil e no Paraná: União Brasileira de Avicultura (UBA); Associação 
Brasileira dos Produtores e Exportadores de Carne de Frango (ABEF); Associação Brasileira dos Produtores de Pinto de Corte (APINCO); Associação Nacional dos Fabricantes de Equipamentos para Aves e Suínos (ANFEAS); Sindicato das Indústrias de Produtos Avícolas do Estado do Paraná (SINDIAVIPAR); Associação dos Avicultores do Oeste do Paraná (AAVIOPAR).

Destaca-se o fato de empresários ligados ao setor avícola assumirem cargos políticos, por exemplo, no caso do Paraná, os parlamentares: deputado estadual Elio Lino Rusch (DEM), que possui aviários integrados à Copagril, no município de Marechal Cândido Rondon; deputado federal Alfredo Kaefer (PSDB), que compõe a sociedade da empresa familiar Kaefer Agroindustrial, controladora da marca Globoaves, de Cascavel-PR.

De acordo com Hespanhol (1997), a classe patronal rural que usufruiu da modernização e dos subsídios governamentais continua com peso político por meio da bancada ruralista que é representante de organizações, tais como: Confederação da Agroindústria e Pecuária do Brasil (CNA), União Democrática Ruralista (UDR), Organização das Cooperativas do Brasil (OCB), a fim de defender uma política que os favoreça diretamente, ignorando os agricultores marginalizados do processo produtivo.

\section{Considerações finais}

A formação de cooperativas agrícolas é reconhecida como um mecanismo clássico para auxiliar o fortalecimento dos produtores rurais em torno de objetivos comuns. Teoricamente, o que se espera da participação cooperativista está além da tarefa de produzir frangos ou outras matériasprimas, pois envolveria uma participação mais ativa no controle dos resultados da produção entregue às cooperativas.

A avicultura é um segmento altamente competitivo em que grandes empresas lideram o mercado. As cooperativas, portanto, atuam como canais alternativos para os avicultores. 
Normalmente, os membros do conselho de administração e os presidentes das cooperativas pesquisadas também são proprietários de aviários. Neste sentido, a gestão das empresas cooperativistas é peculiar e pode influenciar positivamente o tratamento dado ao conjunto dos associados integrados à produção de frangos. Por outro lado, a integração de agricultores às cooperativas agrícolas promove uma relação mais ampla destes produtores de frangos com o ambiente que permeia os sistemas agroindustriais.

Os agentes da cadeia produtiva do frango têm ampliado as exigências quanto à capacitação profissional, ao recebimento de novas tecnologias, ao cumprimento da legislação ambiental e à incorporação de modernas técnicas de produção tanto das indústrias como dos agricultores. Estas mudanças ou adaptações, somadas às oscilações do mercado mundial, podem comprometer a permanência dos produtores na atividade, especialmente dos menores.

O acesso ao crédito condiciona o início e a manutenção dos produtores nesta atividade, pois a produção de frangos é alvo de uma indústria que ao longo dos anos incorporou novas tecnologias, demandando constantes atualizações e investimentos. Neste aspecto, as cooperativas oferecem assistência técnica aos agricultores.

Contudo, há mais de quarenta anos, no Brasil, os contratos de parceria entre produtores e agroindústrias fazem do sistema de produção integrada uma relação exitosa do ponto de vista da gestão agroindustrial. Sabe-se que os contratos dão coordenação à cadeia produtiva. No Oeste Paranaense, a relação contratual entre produtores e agroindústrias é preenchida pela relação cooperativista, ou seja, o integrado é associado da empresa integradora. Tal especificidade é mais importante na medida em que ocorrerem efeitos positivos sobre a melhoria de renda e a qualidade de vida dos produtores. 


\section{REFERÊNCIAS}

BELUSSO, Diane. A integração de agricultores às cooperativas agrícolas abatedoras de frangos no oeste do Paraná (Tese de Doutorado). Presidente Prudente: UNESP, Programa de Pós-Graduação em Geografia (PPGG), 2011, $219 p$.

BIALOSKORSKI NETO, Sigismundo. Aspectos econômicos das cooperativas. Belo Horizonte: Mandamentos, 2006.

COPACOL - Cooperativa Agroindustrial Consolata. Balanço Social 2006. 24p.

COPAGRIL - Cooperativa Agroindustrial Copagril. Relatório Anual 2007. 32p.

ESPÍNDOLA, Carlos José. As agroindústrias no Brasil: o caso Sadia. Chapecó: Grifos, 1999.

ESPÍNDOLA, Carlos José. A cadeia produtiva de frango de corte na América do Sul: considerações preliminares. In: 12 Encontro de Geógrafos da América Latina, 03 a 07 de abril de 2009, Montevidéu, Uruguai. Disponível em: <http://egal2009.easyplanners.info> Acesso em: 13/05/2009.

HESPANHOL, Antonio Nivaldo. Políticas públicas, modernização e crise da agricultura brasileira. Faz Ciência: Revista de Ciências Humanas. Francisco Beltrão - PR: Facibel, v.1, n.1, 1997, pp.38-49.

LAR - Cooperativa Agroindustrial Lar. Relatório Anual 2007. 36p.

LOPES, F. F.; NEVES, M. F.; TROMBIN, V. G. Montando contratos sustentáveis. In: NEVES, Marcos Fava. (coord.). Agronegócios e Desenvolvimento Sustentável: Uma Agenda para a Liderança Mundial na Produção de Alimentos e Bioenergia. São Paulo: Atlas, 2007, pp. 67-72.

OCEPAR. SESCOOP-PR - Organização das Cooperativas do Estado do Paraná. Serviço Nacional de Aprendizagem do Cooperativismo. Informe Diário, n. 2.282, 09 de fevereiro de 2010. Disponível em: <http:/www.ocepar.org.br> Acesso em 12/02/2010.

OCEPAR. SESCOOP-PR - Organização das Cooperativas do Estado do Paraná. Serviço Nacional de Aprendizagem do Cooperativismo. Informe Diário, n. 2.373, 23 de junho de 2010. Disponível em: <http:/www.ocepar.org.br> Acesso em 27/06/2010.

PAULILO, Maria Ignez Silveira. Produtor e Agroindústria: Consensos e Dissensos. Florianópolis: Editora da UFSC, 1990, 182p.

SALANEK FILHO, Pedro. Capital social e cooperativismo agropecuário no processo de desenvolvimento sustentável local: uma avaliação da região de atuação da cooperativa Copacol (Dissertação de Mestrado). Curitiba: UNIFAE - Mestrado em Organização e Desenvolvimento, 2007, 160p. 
SERRA, Elpídio. Cooperativismo empresarial e suas contradições: o distanciamento entre a teoria e a prática do sistema. In: V Encontro de Pesquisadores Latino-Americanos de Cooperativismo, (CD ROM), Ribeirão Preto, São Paulo, Brasil, USP, 06 a 08 de agosto de 2008, 11p.

SESCOOP. Serviço Nacional de Aprendizagem do Cooperativismo. $<$ http://www.portaldocooperativismo.org.br/sescoop/faq/faq1.asp $>$ Acesso em: 18/07/2009.

TEDESCO, João Carlos. Contratualização e racionalidade familiar. In: TEDESCO, J. C. (org.). Agricultura familiar: realidades e perspectivas. 3ed. Passo Fundo-RS: UPF, 2001, pp.107-148. 